\title{
Organizational Commitment and Job Burnout among Psychaitric Nurses in Punjab Pakistan
}

\author{
Kashifa Yasmin \\ PhD Candidate, UUM College of Arts and Sciences \\ Universiti Utara Malaysia \\ Email: kashifa.psy@gmail.com \\ Prof. Dr. Najib Ahmad Marzuki \\ UUM College of Arts and Sciences, Universiti Utara Malaysia \\ Email: najib320@uum.edu.my \\ Doi:10.5296/ jsr.v6i2.8693 URL: http://dx.doi.org/10.5296/ jsr.v6i2.8693
}

\begin{abstract}
Job burnout issue is an increasingly important phenomenon in Asian countries. Based on the model of casual turnover this study assessed the direct effect of organizational commitment on job burnout. The cross sectional data was collected from three hundred five nurses of psychiatric hospitals in Punjab, Pakistan. Structural equation modeling was applied to achieve the objectives. The results revealed that only and normative commitment have significant impact while affective commitment and continuous commitment has not significant effect on nurse's job burnout. So, the commitment of nurse to hospital goals, missions, and values is not enough to predict her job burnout in the hospital. This study recommends that future researchers should examine the impact of work environment on job burnout as a unidimensional. This study contributes socially and economically.
\end{abstract}

Keywords: Job Burnout, Organizational Commitment, Affective Commitment, Continuance Commitment, Normative Commitment 


\subsection{Introduction}

In most medical institutions, the nursing department is the largest department, and nursing staff comprise $40-60 \%$ of total human resources. Nurses tend to be the most numerous component of medical teams and tend to have the longest and closest contact with patients. Therefore, nursing quality affects the overall image of a hospital and can even indirectly affect hospital operations. In recent years, the demand for nurses has increased in response to growth in the elderly population and changes in lifestyles and treatment-seeking behavior Chang CS, Chen SY, Lan YT. 2013; Chang CS, Chang HC. (2009). However, a shortage of clinical nurses has increased workloads and extended working hours. Nurses often have low morale, which causes high turnover. This affects the overall efficiency and quality of medical service in hospitals. Therefore, the organizational commitment of nurses has become a major issue in the nursing science literature.

Nurses' turnover rates have increased significantly leading to a challenge facing healthcare institutions and are growing annually. For instance, the American Health Care Association (2012) reported that the turnover rate among the hospital nurses in the United States (US) has increased to $45 \%$ in all nursing facilities. Such high rates were reported in other countries including 19.9\% in Canada O'Brien-Pallas, L., Murphy, G., Shamian, J., Li, X. and Hayes, L. (2010), and 36.6\% in Jordan Hayajneh, Y., AbuAlRub, R., Athamneh, A. and Almakhzoomy, I. (2009). Moreover, the 5-year nursing turnover in Taiwan was reported to be 50\% Shih, H., Chen, J., Lee, J., Yeh, M. and Tung, T. (2014). These high turnover rates constitute a major contributor to the problem of nursing shortage.

Pakistan is no more different from all over the world which is also facing the problem of the shortage of nurses. The Joint Learning Initiative Report in 2004 and the World Health Report in 2006 show that Pakistan stands at a prominent place among those fifty seven countries which are facing critical workforce deficiencies. This happens due to exporting of nurses to the Gulf countries (Nishtar, 2011). Nurses from Pakistan are quitting from their jobs and are joining Singapore, USA, Malaysia, UK and Gulf countries (Ivković, 2011).

Meyer, Stanley, Herscovitch, and Topolnytsky (2002) conducted a meta-analysis to assess the relationships of the three components of commitment, affective, continuance, and normative with different work related behaviors. Meyer et al. found that the three components of organizational commitment were negatively associated with turnover intentions. In addition, one of the recommendations of the meta-analysis conducted by Meyer et al. (2002) is the need to examine the concept of organizational commitment across cultures to get in depth understanding of the concept globally.

Though many studies had been conducted on burnout among nurses in Nigeria, but most of these studies had not critically looked at burnout and psychological distress among this professional group. The present study is therefore an attempt to explore organizational commitment and job burnout among psychiatric nurses in a Pakistan on how to reduce the negative consequences of organizational commitment and job burnout among nurses and professionals in the health sector and also help to add to the health promotion campaign of the government. 


\subsection{Theoretical Framework}

However, most of the above mentioned studies have cross-sectional designs, meaning that personality dimensions and burnout were examined at the same time, which could result in higher correlations between them. Furthermore, many studies examined burnout in relation to attitudes toward work, most frequently work satisfaction, job involvement, and organizational commitment. Organizational commitment is defined as a degree to which a person identifies himself or herself with the organization and its goals (Stinglhamber F, Bentein K, Vandenberghe C. 2002). The model of organizational commitment that received considerable empirical support identified 3 components: affective (value-based), normative (obligation-based), and continuance (based on an assessment of costs and benefits) (Meyer JP, Allen NJ, Smith CA. 1993). Organizational commitment serves as a protective factor from negative health outcomes and decreases negative effects of stressors on burnout (Schmidt KH. 2007).

Güneş, Bayraktaroğlu \& Kutanis (2009) realized a research by using Maslach Burnout Inventory and found a negative relation between job burnout levels and organizational commitments of employees. In their study, Marmaya et al. (2011) performed an analysis of affective commitment, continuance commitment and normative commitment, which are three sub-dimensions of organizational commitment, and organizational job burnout upon 50 employees, and in the result of this study, they found that the affective commitment dimension of organizational commitment was the only one that affects job burnout.

Chuo (2003) and Basami, A., Chizari, M., \& Abbasi, E. (2013) studied the relationship between organizational commitment and job burnout as well as the predictors of these two variables for a better understanding of productive working environments. The results of this study showed that normative commitment is a better predictor of job burnout in comparison with affective and continuance commitments. In addition, the results suggest that based on measurement of organizational commitment using responsibility and obligation, normative commitment plays an important role in contributing to burnout.

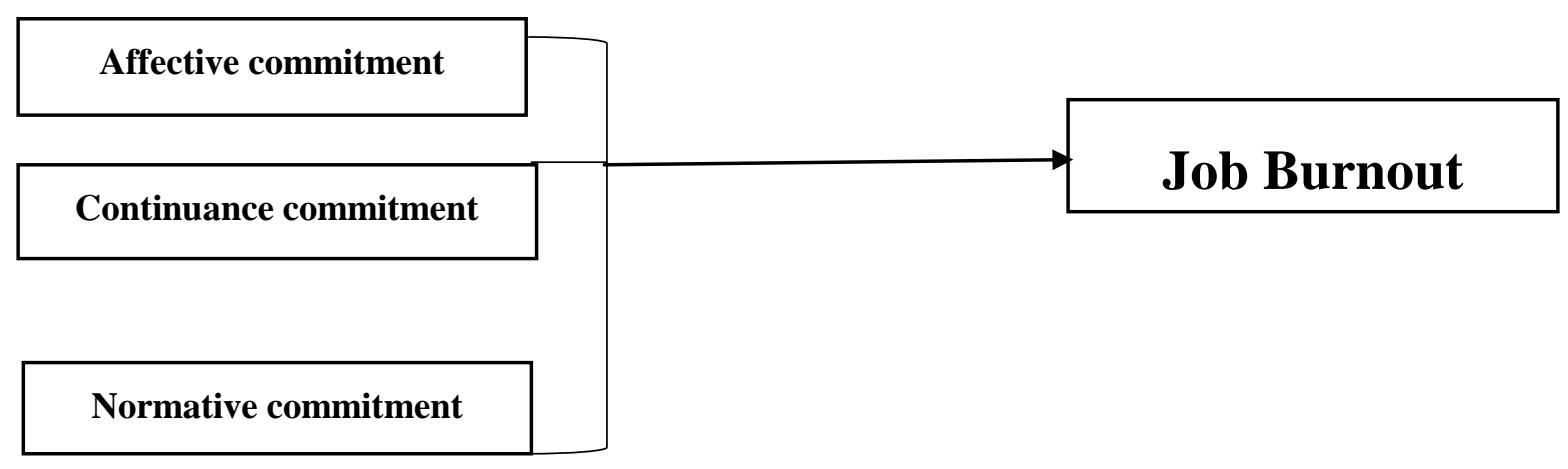

Fig 1.1: framework of the study

Halbesleben (2004) carried out a research on human services personnel such as nurses, low-income employees, police force staff, and office secretaries and studied the consequences of high job burnout and low organizational commitment and concluded that high job burnout and low organizational commitment lead to low spirit of the personnel, their poor 
performance, exhaustion, absenteeism, high rate of leaving or changing their jobs, disturbance in providing office services and other administrative and service-related problems and issues. The worst impact of job burnout at the organizational level is destroying and diminishing organizational commitment among personnel and experts of the job. Therefore, organizational commitment has been a subject of much interest in the area of organizational development. One of the important findings in the theoretical literature of job burnout is that organizational commitment is negatively related to job burnout. The organizational commitment level of an individual increases with their contribution to and involvement in the issues related to the organization and this matter per se decreases their chances of affliction with burnout (Halbesleben, JRB and, Buckley, MR., 2004).

\subsection{Relationship between Organizational Commitment (dimensions) and Job Burnout}

Low levels of organizational commitment have been found to influence job burnout in hospital employees (Kalliath, O’Driscoll, \& Gillespie, 1998).

Organizational commitment can affect job commitment because an employee who has a sense of belonging and commitment to the organization is unlikely to tire from the job, and this effect can be even more significant in collectivist cultures, Tan D, Akhtar S (1998). While the relationship between any two of the three variables is relatively clear, the relationship of these three variables has not been explored. Nursing is a high risk, high pressure, and labor-intensive profession, and thus, a high incidence of job burnout exists among nurses. A survey conducted in five countries, including the United States, revealed that job burnout is a very serious phenomenon within the nursing profession. Among the five countries surveyed, $40 \%$ of the nurses in four countries experienced job burnout,(Aiken LH, Clarke SP, Sloane DM, Sochalski JA, Busse R et al. 2001).

Organizational commitment refers to the attitude towards the organization. This attitude is a psychological bond in the relationship between an employee and the organization that affects the degree to which the individual identifies with the goals and values of the organization, exerts effort to achieve organizational goals, and desires to remain in the organization Sheldon M (1971); Sivarajasingam V, Shepherd J, Matthews K, Jones S (2002). The three-factor model of organizational commitment proposed by Meyer and Allen, which includes affective, continuance, and normative,Meyer JP, Allen NJ (1991), has been well-received and supported by international studies,(Dunham RB, Grube JA, Castaneda MB (1994); Fan Y, Zhang X, Yan J. 2012). Affective commitment refers to the emotional attachment that employees feel towards their organization. Continuance commitment refers to the awareness of employees of the cost of losing their membership in the organization. Normative commitment refers to the level of consistency between the values of the individual and the organization or the sense of responsibility for the organization, which is shaped by the long-term influence of society on the sense of social responsibility of an individual. A large body of research supports the relationship between organizational commitment and job burnout. King and Sethi found that organizational commitment has a moderating effect on the relationship between stress and job burnout,King R, Sethi V (1997). Tan and Akhtar reported that when age, tenure, organizational level, and work perceptions of Chinese employees were 
controlled, organizational commitment had a significant effect on experienced job burnout,Tan D, Akhtar S (1998). Wright and Hobfoll further showed that organizational commitment has an effect on every dimension of job burnout,(Wright TA, Hobfoll SE. 2004).

\subsection{Research Methodology}

This section discusses the sampling, measurement and method of the study as follows:

\subsubsection{Sample}

The Population for this study was nurses in psychiatric hospitals in Pakistan. The populations for this study include the nurses who work in the psychiatric hospitals which are placed and situated in Punjab province of Pakistan. Moreover, very limited studies have been conducted which has taken psychiatric public hospitals for studying intention to quit. The study distributed self-administered questionnaires with the help of the contact person in each hospital, following the probability simple random sampling technique. The study distributed 600 questionnaires to the nurses and received back 358 questionnaires from the nurses of which 305 found usable for data analysis purpose. The effective response rate was $59 \%$ and usable questionnaire was $51 \%$.

\subsubsection{Measurement of Organizational Commitment}

This paper used to measure the organizational commitment in the present study, a 22-item questionnaire organizational commitment scale will be adapted from Meyer and Allen (1993). The questionnaire seeks information on the organizational commitment of the hospitals from the perspective of nurses working in psychiatric hospitals. The 22 items are based on the three dimensions namely the affective commitment, continuance commitment and normative commitment. All the 22 items are scored on a 5 point Likert Scale with $1=$ strongly disagree to $5=$ strongly agree.

\subsubsection{Measurement of Job Burnout}

This paper used to measure the job burnout in the present study, 22-item questionnaire job burnout adapted from Maslach, Jackson and Leiter (1996). The questionnaire seeks information on the job burnout of the hospitals from the perspective of nurses working in psychiatric hospitals. All the 22 items which represent physical, emotional, and mental factors. Respondents were asked to mark the responses on five point scale ranging from $1=$ strongly disagree to $5=$ strongly agree.

\subsection{Method}

This study used structural Equation Modeling (SEM) Path analysis, using PLS path model assessment to test the inter-relationship among variables. This study adopted two step approach as suggested by Hair et al. (2014) and Hesler et al. (2009) for conducting the analysis.

\subsection{Results and discussion}

The first step was to assess the measurement of the model for reliability, convergent validity 


\section{Macrothink}

Journal of Sociological Research

ISSN 1948-5468

2015, Vol. 6, No. 2

and discriminant validity. This table below shows how discriminant validity was ascertained by comparing the indicator loading with cross loading. Researchers have suggested that the entire indicators should be greater than the cross loading (Hair et al., 2014; Chin, 1998). Table 1.1 compares the indicator loading with other reflective indicators. All the available indicators are greater than the cross loading, this means the requirement of discriminant validity has been achieved.

Table 1.1

Cross Loading

\begin{tabular}{llllll}
\hline Variable & Item & JB & OCA & OCC & OCN \\
\hline JB & JB1 & $\mathbf{0 . 8 1 5}$ & 0.137 & 0.027 & 0.205 \\
& JB11 & $\mathbf{0 . 6 1 1}$ & 0.139 & 0.255 & 0.205 \\
& JB2 & $\mathbf{0 . 7 7 2}$ & -0.004 & -0.103 & 0.039 \\
& JB20 & $\mathbf{0 . 5 8 6}$ & 0.092 & 0.073 & 0.031 \\
& JB3 & $\mathbf{0 . 6 8 0}$ & 0.108 & -0.001 & 0.109 \\
& JB8 & $\mathbf{0 . 8 2 2}$ & 0.152 & 0.113 & 0.203 \\
& JB9 & $\mathbf{0 . 6 6 9}$ & 0.062 & 0.038 & 0.100 \\
OAC & OCA1 & 0.082 & $\mathbf{0 . 7 6 0}$ & 0.287 & 0.272 \\
& OCA3 & 0.104 & $\mathbf{0 . 6 9 7}$ & 0.290 & 0.176 \\
& OCA4 & 0.012 & $\mathbf{0 . 5 5 4}$ & 0.384 & 0.293 \\
& OCA5 & 0.126 & $\mathbf{0 . 8 9 1}$ & 0.356 & 0.314 \\
OCC & OCA6 & 0.138 & $\mathbf{0 . 8 9 7}$ & 0.371 & 0.324 \\
& OCC1 & -0.004 & 0.136 & $\mathbf{0 . 4 8 0}$ & 0.160 \\
& OCC2 & 0.093 & 0.324 & $\mathbf{0 . 8 5 0}$ & 0.388 \\
& OCC3 & 0.062 & 0.329 & $\mathbf{0 . 8 7 3}$ & 0.352 \\
& OCC4 & 0.070 & 0.391 & $\mathbf{0 . 8 4 3}$ & 0.324 \\
& OCC5 & 0.074 & 0.331 & $\mathbf{0 . 7 1 4}$ & 0.275 \\
OCN & OCN1 & 0.203 & 0.348 & 0.391 & $\mathbf{0 . 9 5 6}$ \\
& OCN4 & 0.138 & 0.247 & 0.350 & $\mathbf{0 . 8 9 3}$ \\
\hline
\end{tabular}


Table 1.2

Convergent Validity Analysis

\begin{tabular}{llllll}
\hline Variables & Item & Loading & AVE & $\begin{array}{l}\text { Cronbach } \\
\text { alpha }\end{array}$ & $\begin{array}{l}\text { Composite } \\
\text { reliability }\end{array}$ \\
\hline Job burnout & JB1 & 0.815 & 0.509 & 0.837 & 0.877 \\
& JB11 & 0.611 & & & \\
JB2 & 0.772 & & & \\
JB20 & 0.586 & & & \\
& JB3 & 0.680 & & & \\
& JB8 & 0.822 & & & \\
Affective commitment & JB9 & 0.669 & & & \\
& OCA1 & 0.760 & 0.594 & 0.841 & \\
& OCA3 & 0.697 & & & \\
& OCA4 & 0.554 & & & \\
OCA5 & 0.891 & & & \\
Continuance commitment & OCA6 & 0.897 & & & \\
& OCC1 & 0.480 & 0.587 & 0.811 & \\
& OCC2 & 0.850 & & & \\
& OCC3 & 0.873 & & & \\
& OCC4 & 0.843 & & & \\
Normative commitment & OCC5 & 0.714 & & & \\
& OCN1 & 0.956 & 0.855 & 0.837 & \\
\hline
\end{tabular}

Table 1.3

Discriminant Validity Analysis

\begin{tabular}{lllll}
\hline Variable & JB & OCA & OCC & OCN \\
\hline JB & $\mathbf{0 . 7 1 3}$ & & & \\
OCA & 0.142 & $\mathbf{0 . 7 7 1}$ & & \\
OCC & 0.082 & 0.404 & $\mathbf{0 . 7 6 6}$ & \\
OCN & 0.190 & 0.331 & 0.403 & $\mathbf{0 . 9 2 5}$ \\
\hline
\end{tabular}

Table 1.3 depicts the composite reliability coefficient of the latent construct. The composite reliability of each construct ranged from .71 to .92 . This connotes internal consistency of the 
scale. The composite reliability of all constructs is above the threshold of .70. The composite reliability as shown in the table is higher than average variance extracted and value of average variance extracted is higher than 0.5 . These results satisfy the criteria as suggested by (Hair et al. 2010) for convergent validity.

According to the finding as shown in table 1.4 the relationship of normative commitment and job burnout was positive and significant $(\beta=0.156$, t-value $=2.348 \mathrm{p}=<0.019)$ while the relation between affective commitment, continuance commitment and job burnout was insignificant $(\beta=0.088$, $t$-value $=1.587 \mathrm{p}=<0.113)(\beta=-0.054$, $\mathrm{t}$-value $=0.715 \mathrm{p}=<0.475)$.

Table 1.4

Result of the Inner Structural Model

\begin{tabular}{lllllll}
\hline H. No & Hypothesis & $\begin{array}{l}\text { Original } \\
\text { Sample }\end{array}$ & $\begin{array}{l}\text { Standard } \\
\text { Error }\end{array}$ & T-Value & P-value & Decision \\
\hline H3 & OCA -> JB & 0.088 & 0.056 & 1.587 & 0.113 & Not supported \\
H5 & OCC -> JB & -0.054 & 0.075 & 0.715 & 0.475 & Not supported \\
H7 & OCN -> JB & 0.156 & 0.066 & 2.348 & 0.019 & Supported \\
\hline
\end{tabular}

$*: \mathrm{p}<0.1 ; * *: \mathrm{P}<0.05 ; * * *: \mathrm{P}<0.01$

\subsection{Conclusion}

Burnout issue is an increasingly important phenomenon in Asian countries. Based on the model of casual turnover this study assessed the direct effect of organizational commitment on job burnout. The cross sectional data was collected from three hundred five nurses of psychiatric hospitals in Punjab, Pakistan. Structural equation modeling was applied to achieve the objectives. The findings showed that the impact of affective commitment and continuance is insignificant and normative commitment was statistically in significant on job burnout. The findings are in contrary to theory. This study extends past literature in the area of job burnout in such a way that it provides empirical evidence and helps to increase the understanding on the impact of organizational commitment nurse's job burnout especially in Pakistan context. Majority of the evidence to date has demonstrating that job burnout have been widely used as multidimensional construct in different approaches such as behavioral approach, attitudinal approach and motivational approach in previous literature (Meyer \& Allen, 1997; Wright TA, Hobfoll SE. 2004; Mayer et al, 2002).

In contrast with previous literature, some studies support the unidimensional construct of job burnout by highlighting the effect of burnout on job outcomes such as organizational commitment is high when multiple forms of burnout are combined to make whole construct such as job burnout (Bersamin, K. K. (2006). Moreover, majority of the previous studies have demonstrated an association rather than impact of job burnout as unidimensional construct on 
employee's attitudes and behavior. So this study also recommends that the in the future studies should examine the impact of work environment (involvement, peer cohesion, supervisor's support, work pressure, clarity and physical comfort) on intention to quit through jobburnout, job burnout should be taken as a unidimensional. There are chances that involvement, peer cohesion, supervisor's support, work pressure, clarity and physical comfort impact on job burnout and intention to quit more than the other factors of work environment because of the difference of organizational culture and social custom of Pakistani society. In the context of area there are numerous research studies on the psychiatry in the developed countries, while from developing countries perspective the contribution is just mere $6 \%$ in the form of article in leading research journals of psychiatry (Gadit, 2007). According to (Gadit, 2007) the top two journals of medical health did not published any article in psychiatry till 1995. From 1995 to 2006 only 106 article on psychiatry were published in the top journal of medical in Pakistan but study did not found any article on nurses of psychiatry (Gadit, 2007). So, this study contributes by conducting research on psychiatric department of nurses and recommends to conduct more studies on the psychiatric nurses in future.

\section{References}

Aiken LH, Clarke SP, Sloane DM, Sochalski JA, Busse R et al. (2001) Nurses' reports on hospital care in five countries. Health Aff (Millwood), 20(3): 43-53.10.1377/hlthaff.20.3.43 PubMed: 11585181[PubMed].

American Health Care Association (2012) 2011 AHCA Staffing Survey Report. http://www.ahcancal.org/research_data/staffing/Documents/2011\%20Staffing\%20Survey\%20 Report.pdf.

Basami, A., Chizari, M., \& Abbasi, E. (2013). Investigating relationship between job burnout and organizational commitment among extension workers in Kurdistan Province, Iran. International Journal of Humanities and Social Science Invention, 10(2), 63-67.

Chang CS, Chang HC. (2009) Perceptions of internal marketing and organizational commitment by nurses. Journal of Advanced Nursing; 65:92-100. doi: 10.1111/j.1365-2648.2008.04844.x.

Chang CS, Chen SY, Lan YT. (2013) Service quality, trust, and patient satisfaction in interpersonal-based medical service encounters. BMC Health Services Research. 13:22. doi: 10.1186/1472-6963-13-22.

Chin, W. W. (1998). The partial least squares approach to structural equation modeling. Modern methods for business research, 295(2), 295-336.

Dunham RB, Grube JA, Castaneda MB (1994) Organizational commitment: The utility of an integrative definition. Journal of Applied Psychology, 79(3): 370-380.10.1037/0021-9010.79.3.370

Dunham, R. B., Grube, J. A., \& Castaneda, M. B. (1994). Organizational commitment: The 
utility of an integrative definition. Journal of Applied psychology, 79(3), 370.

F. Hair Jr, J., Sarstedt, M., Hopkins, L., \& G. Kuppelwieser, V. (2014). Partial least squares structural equation modeling (PLS-SEM) An emerging tool in business research. European Business Review, 26(2), 106-121.

Fan Y, Zhang X, Yan J (2012) Thinking on oppugned questions of three-factor model of organizational commitment. Journal of Xi'an Jiaotong University; (Social Science), 32 (4): $50-56$

Güneş, İ., Bayraktaroğlu, S. and Kutanis, R.Ö. (2009). A Relationship on Organizational Commitment of Emploless and Burnout Level: Sample from a State University, Suleyman Demirel University. The Journal of Faculty of Economics and Administrative Sciences, 143, 481-497.

Hair, J. F., Black, W. C., Babin, B. J., \& Anderson, R. E. (2010). Multivariate data analysis: A global perspective (7th ed.). Upper Saddle River, NJ: Pearson Education.

Halbesleben, J. R., \& Buckley, M. R. (2004). Burnout in organizational life. Journal of management, 30(6), 859-879.

Hayajneh, Y., AbuAlRub, R., Athamneh, A. and Almakhzoomy. (2009) Turnover Rate among Registered Nurses in Jordanian Hospitals: An Exploratory Study. International Journal of Nursing Practice, 15, 303-310. http://dx.doi.org/10.1111/j.1440-172X.2009.01758.x.

Ivković, M. (2011). International nurse migrations: Global trends. Journal of the Geographical Institute Jovan Cvijic, 61(2), 53-67.

Kalliath, T. J., O’Driscoll, M. P., \& Gillespie, D. F. (1998). The relationship between burnout and organizational commitment in two samples of health professionals. Work \& Stress, 12(2), 179-185.

King R, Sethi V (1997) The moderating effect of organizational commitment on burnout in information systems professionals. European Journal of Information Systems, 6(2): 86-96.10.1038/sj.ejis.3000259.

Labatmediene, L., Endriulaitiene, A., \& Gustainiene, L. (2007). Individual correlates of organizational commitment and intention to leave the organization. Baltic Journal of Management, 2(2), 196-212.

Lindblom, K. M., Linton, S. J., Fedeli, C., \& Bryngelsson, L. (2006). Burnout in the working population: relations to psychosocial work factors. International journal of behavioral medicine, 13(1), 51-59.

M. Chuo, (2003) A study of the relationship between organizational commitment and burnout. In organizational psychology, Alliant International University, PhD dissertation.

Marmaya, N.H., Zawawi, N., Hitam, M. and Jody, J.M. (2011) Organizational Commitment and Job Burnout among Employees in Malaysia. International Conference on Business and Economics Research, 1, 185-197. 
Maslach, C., Jackson, S. E., \& Leiter, M. P. (1996). Maslach burnout inventory manual. Mountain View, CA: CPP. Inc., and Davies-Black.

Meyer JP, Allen NJ (1991)A three-component conceptualization of organizational commitment. Human Resource

Management

Review, 1(1):

61-89.10.1016/1053-4822(91)90011-Z

Meyer JP, Allen NJ, Smith CA. Commitment to organizations and occupations: extension and test of a three-component conceptualization. J Appl Soc Psychol. 1993; 78:538-51. doi: 10.1037/0021-9010.78.4.538.

Meyer JP, Stanley DJ, Herscovitch L, Topolnytsky L (2002) Affective, continuance, and normative commitment to the organization: A meta-analysis of antecedents, correlates, and consequences. Journal of Vocational Behavior, 61(1): 20-52.10.1006/jvbe.2001.1842

Meyer JP, Stanley DJ, Herscovitch L, Topolnytsky L. Affective, continuance, and normative commitment to the organization: A meta-analysis of antecedents, correlates, and consequences. Journal of Vocational Behavior. 2002; 61(1):20-52.

Meyer, J. P., Allen, N. J., \& Smith, C. A. (1993). Commitment to organizations and occupations: Extension and test of a three-component conceptualization. Journal of applied psychology, 78(4), 538.

Nishtar, S., \& Mehboob, A. B. (2011). Pakistan prepares to abolish Ministry of Health. The Lancet, 378 (9792), 648-649.

O'Brien-Pallas, L., Murphy, G., Shamian, J., Li, X. and Hayes, L. (2010) Impact and Determinants of Nurse Turnover: A Pan-Canadian Study. Journal of Nursing Management, 18, 1073-1086. http://dx.doi.org/10.1111/j.1365-2834.2010.01167.x.

Posig, M., \& Kickul, J. (2003). Extending our understanding of burnout: Test of an integrated model in nonservice occupations. Journal of Occupational Health Psychology, 8(1), 3.

Schaufeli, W., \& Enzmann, D. (1998). The burnout companion to study and practice: A critical analysis. CRC press.

Schmidt KH. Organizational commitment: a further moderator in the relationship between work stress and strain? Int J Stress Manag. 2007; 14:26-40. doi: 10.1037/1072-5245.14.1.26.

Sheldon M (1971) Investments and involvements as mechanisms producing commitment to the organization. Administrative Science Quarterly: 143-150

Shih, H., Chen, J., Lee, J., Yeh, M. and Tung, T. (2014) Determinants and Impact of Turnover Rate among Nursing Staff: The Exploratory Retrospective Follow-Up Study in Taiwan. Asia Life Sciences, 23, 175-185.

Sivarajasingam V, Shepherd J, Matthews K, Jones S (2002) Trends in violence in England and Wales 1995-2000: an accident and emergency perspective. Journal of Public Health, 24(3): 219-226.10.1093/pubmed/24.3.219 [PubMed] 


\section{Macrothink}

Journal of Sociological Research

ISSN 1948-5468 2015, Vol. 6, No. 2

Stinglhamber F, Bentein K, Vandenberghe C. Extension of the three-component model of commitment to five foci. Eur J Psychol Assess. 2002;18:123-38. doi: 10.1027//1015-5759.18.2.123.

Tan D, Akhtar S (1998) Organizational commitment and experienced burnout: An exploratory study from a Chinese cultural perspective. International Journal of Organizational Analysis, 6(4): 310-333.10.1108/eb028889.

Wright TA, Hobfoll SE (2004) Comm1.itment, psychological well-being and job performance: An examination of conservation of resources (COR) theory and job burnout. Journal of Business and Management, 9(4): 389-406. 